\title{
Review of: "A low direct electrical signal attenuates oxidative stress and inflammation in septic rats"
}

\author{
Amany Sayed ${ }^{1}$
}

1 Cairo University

Potential competing interests: The author(s) declared that no potential competing interests exist.

The idea is novel and it is good era for bacterial treatment. But, many researches are required to confirm this idea. Also, some explanations are required for the future researches such as;

- Authors wrote that electrical signal has antibacterial, antioxidant, and anti-inflammatory effects without producing any tissue damage. How? Are authors study the different tissues deeply to deduce this sentence?. In my opinion, this this impossible.

- Can authors explain how the electrical signal has antioxidant effect? 